Aim and Methods We conducted a prospective study over a 17-month period (June 2011-November 2012) to determine shortterm clinical outcomes in the whole cohort of infants born at $>35$ weeks gestation who had an arterial cord or first hour $\mathrm{pH}$ of $\leq 7.10$.

Abstract PL.12 Table 1 Short-term clinical outcomes of infants born with perinatal acidosis

\begin{tabular}{llll}
\hline Outcomes & $\begin{array}{l}\text { All Infants } \\
\mathbf{N}=\mathbf{6 9}\end{array}$ & $\begin{array}{l}\text { Not Cooled } \\
\mathbf{N}=\mathbf{5 7}\end{array}$ & $\begin{array}{l}\text { Cooled } \\
\mathbf{N}=\mathbf{1 2}\end{array}$ \\
\hline HIE any grade & $31(45 \%)$ & $19(33 \%)$ & $12(100 \%)$ \\
$\quad$ HIE grade 1 & $13(19 \%)$ & $11(58 \%)$ & $2(17 \%)$ \\
$\quad$ HIE grade 2 & $12(17 \%)$ & $6(31 \%)$ & $6(50 \%)$ \\
$\quad$ HIE grade 3 & $6(08 \%)$ & $2(10 \%)$ & $4(33 \%)$ \\
Clinical Seizures & $16(23 \%)$ & $9(16 \%)$ & $7(58 \%)$ \\
Respiratory Support & $24(35 \%)$ & $14(24 \%)$ & $10(83 \%)$ \\
Hypoglycaemia & $18(26 \%)$ & $14(24 \%)$ & $4(33 \%)$ \\
Feeding problems & $48(69 \%)$ & $36(63 \%)$ & $12(100 \%)$ \\
Age at full Suck Feeds & $1(0-13)$ & $1(0-13)$ & $6(1-13)$ \\
Median (range), days & & & \\
Age at discharge home & $3(0-23)$ & $2(0-16)$ & $10(3-23)$ \\
Median (range), days & & & \\
Died & $1(1)$ & 0 & $1(8)$ \\
\hline
\end{tabular}

Results 69 infants were admitted with severe acidosis. CTG abnormalities were present in $71 \%$ of cases. Overall, 31/69 (35\%) infants showed signs of hypoxic-ischaemic encephalopathy (HIE) and 12/69 (17\%) were cooled. Of non-cooled infants, $8 / 57$ (14\%) developed moderate-severe HIE (Table 1).

Conclusion Short term morbidities are common in the whole cohort of infants born with severe perinatal acidosis, including in infants initially evaluated as not meeting current criteria for cooling.

\section{PL.13 EXPERIENCES OF WOMEN AND FAMILIES IN ALONGSIDE MIDWIFERY UNITS; TACKLING THE BOTTLENECKS AND CRITICAL TOUCHPOINTS}

doi:10.1136/archdischild-2013-303966.197

'S Rance, ${ }^{2} \mathrm{~J}$ Rayment, ${ }^{2} \mathrm{C}$ McCourt, ${ }^{1,2} \underline{\mathrm{J} \text { Sandall. }}{ }^{1} \mathrm{King}$ 's College, London, London, UK; ${ }^{2}$ City University, London, UK

Background Alongside midwifery units (AMUs) provide care for women deemed 'low-risk' and Birthplace in England found that low risk women received significantly fewer interventions in AMUs compared to obstetric units with no difference in perinatal outcomes. The number of AMUs are increasing, however, little is known regarding

How to organise services to improve quality, safety and women's experiences.

Women's experiences

Aim and Methods A Birthplace follow-on study investigated AMU organisation from users' and professionals' perspectives. Case study of AMU in 4 NHS Trusts across England. Data collected November 2011 - October 2012: observations (>100 hours); semi-structured interviews with staff, managers and stakeholders $(n=89)$ and postnatal women and birth partners $(n=47)$.

Results We found several critical touchpoints. Women had unequal access to information enabling them to choose and engage with midwife-led care. Women often experienced care inside AMUs as excellent, but system and provider generated issues in admission and transfer led to difficulties for some in gaining access in early labour. Factors enabling women to feel safe included accompaniment by partners; perception of personalised assessment of progress in labour; being assured of appropriate pain relief, timely transfer if required, and staff prepared to listen, inform, and acknowledge their concerns and needs.
Conclusion Greater attention needs to be given to woman-centred care at the critical interface between midwife led settings with antenatal services and OUs.

PL.14 WOMEN'S JOURNEYS THROUGH BIRTHPLACE
SETTINGS: ANALYSIS OF THE MANAGEMENT AND
EXPERIENCE OF ESCALATION AND TRANSFER DURING
LABOUR AND BIRTH

doi:10.1136/archdischild-2013-303966.198

1J Sandall, 'S Rance, ${ }^{2} \mathrm{~J}$ Rayment, ${ }^{2} \mathrm{C}$ McCourt. ${ }^{1} \mathrm{King}$ 's College, London, London, UK; ${ }^{2}$ City University, London, UK

Introduction Birthplace in England found that transfer rates for first time mothers planning to give birth at home, or in a midwife led unit ranged between 36 and 45\%. Delays in escalation, transfer and response are a quality and safety issue.

Aim Our overall aim was to describe and explore features of maternity care systems that may have affected the provision of high quality and safe care in different birth settings. This paper presents the experiences of women and families of their journey through the maternity system.

Methods Organisational case studies in 4 NHS Trusts in 4 health regions in England. Data collected from March 2010 to December 2010 included: observation of meetings and ward life (>150 hours); semi-structured interviews with staff, managers and external stakeholders ( $\mathrm{n}=86)$; postnatal women and birth partners $(\mathrm{n}=72)$.

Results The 3 delays model (1) escalation (2) transfer (3) treatment was drawn upon to analyse how women's journeys through different birth settings were managed and experienced. Most women felt prepared for the unpredictability of events, and some experienced transfer and handover with feelings of worry, disempowerment or disappointment. Some felt unable to ask about options with professionals, although careful explanation by professionals was a common theme in positive narratives by women and partners.

Implications The study found wide variation in the organisation and delivery of home birth services compared to other settings. Successful management of escalation and transfer requires an understanding variation and gaps in systems, addressing boundaries that delay effective transfer and escalation of care.

PL.15 ARE OBSTETRICIANS NORMAL? PERSONAL BIRTH CHOICES
AND OUTCOMES OF SOUTH WEST OBSTETRICIANS AND
GYNAECOLOGISTS; WITH COMPARISON TO REGIONAL AND
NATIONAL BIRTH STATISTICS

doi:10.1136/archdischild-2013-303966.199

${ }^{1} \mathrm{~K}$ Lightly, 'EH Shaw, ${ }^{2} \mathrm{~N}$ Dailami, 'D Bisson. ' Southmead Hospital, Bristol, UK; ${ }^{2}$ University of West UK, Bristol, UK

Objectives Publication of NICE caesarean section guideline reestablished debate about whether obstetricians fear childbirth. This study aimed: To determine personal choices of practising obstetricians on mode of delivery for themselves or their partners in various clinical scenarios; To determine actual rates of modes of deliveries amongst obstetricians and gynaecologists in South West (SW) England.

Methods A piloted online survey link was sent to all obstetricians and gynaecologists (consultants and trainees) in SW England using a robust email database. Obstetricians mode of delivery data between 2006-2011 was compared to regional/national population data, using Hospital Episode Statistics (HES)

Results Response rate: 165/242 (68\%). 89.9\% of SW obstetricians stated they would plan vaginal delivery for themselves/their partners; $10.1 \%$ would opt for caesarean section in an uncomplicated primiparous pregnancy. 